\title{
The effect of social interaction and environment during aerobic dance on salivary cortisol
}

\author{
DOI: https://doi.org/10.5114/pq.2020.95770
}

\author{
Nia Sri Ramania, Maria Immaculata Iwo, Tommy Apriantono, Bagus Winata \\ Faculty of Sports Science, Bandung Institute of Technology, Bandung, Indonesia
}

\begin{abstract}
Introduction. Aerobic dance can reduce individual stress response levels and its psychosomatic symptoms, and increase physical fitness. The effect of social interaction and the environment is also considered prominent for reducing stress. The purpose of this study was to measure the impact of social interaction and the environment when practising aerobic dance on reducing stress among first-rate university students in Indonesia.

Methods. The study involved 16 students ( 8 males and 8 females) aged 18-20 years. All participants took a series of indoor and outdoor tests. In the indoor-test phase, they did indoor aerobic dance without communicating with one another, while in the outdoor-test phase, they did outdoor aerobic dance and were allowed to interact with one another. The subjects underwent 3 measurements: salivary cortisol was assessed before and after the aerobic dance in the indoor and outdoor test; heart rate was evaluated during the aerobic dance; and rating of perceived exertion was established immediately after each participant had finished the aerobic dance.

Results. One-way ANOVA statistical test showed a significant difference between indoor-test and outdoor-test conditions in the measurement of salivary cortisol after the intervention $(p=0.001)$. Independent t-test also revealed a significant difference between both conditions ( $p=0.001)$.

Conclusions. More communicative social interactions and conducive outdoor environments that allowed a direct contact with nature in doing aerobic dance had a significant effect in reducing cortisol awakening response in salivary cortisol measurements. Key words: exercise training, outdoor, physical stress, psychology, sport therapy, indoor
\end{abstract}

\section{Introduction}

With $268,074,600$ inhabitants, Indonesia is the $4^{\text {th }}$ most populous country in the world [1]. As a country with high population density, it faces a quite serious problem of lack of participation of the Indonesian society in physical activity [2]. The issue refers to people of various age ranges, including young children (aged 5-11 years) and adolescents (17-25 years). They now prefer playing gadgets to doing physical activity [3]. In turn, those in the category of early adulthood (26-35 years) and late adulthood (36-45 years) experience difficulty in doing physical activity because of their busy working hours [4]. Furthermore, the Ministry of Health of Indonesia stated that obesity and stress were among the symptoms and effects of limited participation of the Indonesian society in physical activity [5].

Nowadays, aerobic dance is very popular in various parts of the world [6]. Quin et al. [7] explained that aerobic dance is a developing kind of sport, favoured by the society for several reasons, such as ease of practice anywhere, alone or together with other people, or low cost. Moreover, several previous studies revealed the benefits of carrying out aerobic dance. According to Duberg et al. [8], aerobic dance can reduce the level of individual stress responses, decrease its psychosomatic symptoms, and increase one's physical fitness. Specifically, Jeong et al. [9] concluded that aerobic dance exerted beneficial effects on decreasing anxiety and depression and improved memory and cognitive function as compared with individuals who did not practise it. Interestingly, no one has reported disadvantages of doing aerobic dance for the functions of human physiology and psychology.

Meanwhile, in some studies observing aerobic dance, the benefit of reducing stress in the society is relatively well documented [10-12]. However, those studies lack detailed evidence related to measurements of physiology biomarkers used to investigate the effect of social interaction and the environment of aerobic dance on stress reduction. For example, Quin et al. [7] concluded that aerobic dance could reduce stress and its psychosomatic symptoms in children, but they did not provide concrete measurement results, such as maximum heart rate of each participant in aerobic dance [13] or salivary cortisol or serum cortisol as a parameter to determine the stress level of each individual [14].

In line with this, without any intention to diminish the value of benefits of the study conducted by Quin et al. [7], we noted that there was also no attention to several other factors that can influence stress reduction, such as environment and social interaction in doing aerobic dance, which are essential for decreasing stress. Some of the previous studies have observed the impact of social interaction [15-18] and environment. Specifically, Woodward et al. [15] explained that social interaction was very important to reduce stress among people who are socially disadvantaged, and Blase and Waning [19] implied that creating a calm environment protocol would help in the process of meditation, as it could produce benefits in the focus of attention, happiness, and ability to regulate and adjust emotions.

In the context of the interest and some problems found

Correspondence address: Nia Sri Ramania, Faculty of Sports Science, Institut Teknologi Bandung, Ganesha No. 10, Lb. Siliwangi, Kecamatan Coblong, Kota Bandung, Jawa Barat 40132, Indonesia, e-mail: nia@fa.itb.ac.id

Received: 19.11 .2019

Accepted: 09.01.2020

Citation: Ramania NS, Iwo MI, Apriantono T, Winata B. The effect of social interaction and environment during aerobic dance on salivary cortisol. Physiother Quart. 2020;28(3):14-20; doi: https://doi.org/10.5114/pq.2020.95770. 
in previous studies in measuring the benefits of aerobic dance for the functions of human physiology and psychology, the purpose of this study was to measure the influence of social interaction and environment when doing aerobic dance on reducing stress among first-rate university students in Indonesia. The study hypothesized that more communicative social interactions and a more conducive environment in doing aerobic dance would have a more significant effect on reducing stress as evidenced by decreased salivary cortisol levels in each individual.

\section{Subjects and methods}

\section{Participants}

The study involved 16 first-year students ( 8 males and 8 females) of Bandung Institute of Technology, aged 18-20 years, recruited with the following criteria: no history of chronic illness (e.g. cardiovascular), no injury during the previous 3 months, active practice of aerobic dance with a minimum intensity of 3 hours of training per week, not smoking and no smoking history, no mental or physical impairment, and no previous or present intake of psychoactive substances. Before the study, all participants received an explanation of its procedure and risks.

The study engaged gymnastic instructors $(n=2)$, who had a special certificate to provide aerobic dance training. A decoration team $(n=2)$ arranged modifications related to the outdoor to support the aerobic dance to run conducive. Besides, a nutrition team $(n=2)$ monitored the participants and completed a consecutive dietary record over 3 days prior to the study to assess the adequacy of nutrient intake. The participants' diet was based on a diet calculation method (Bil-

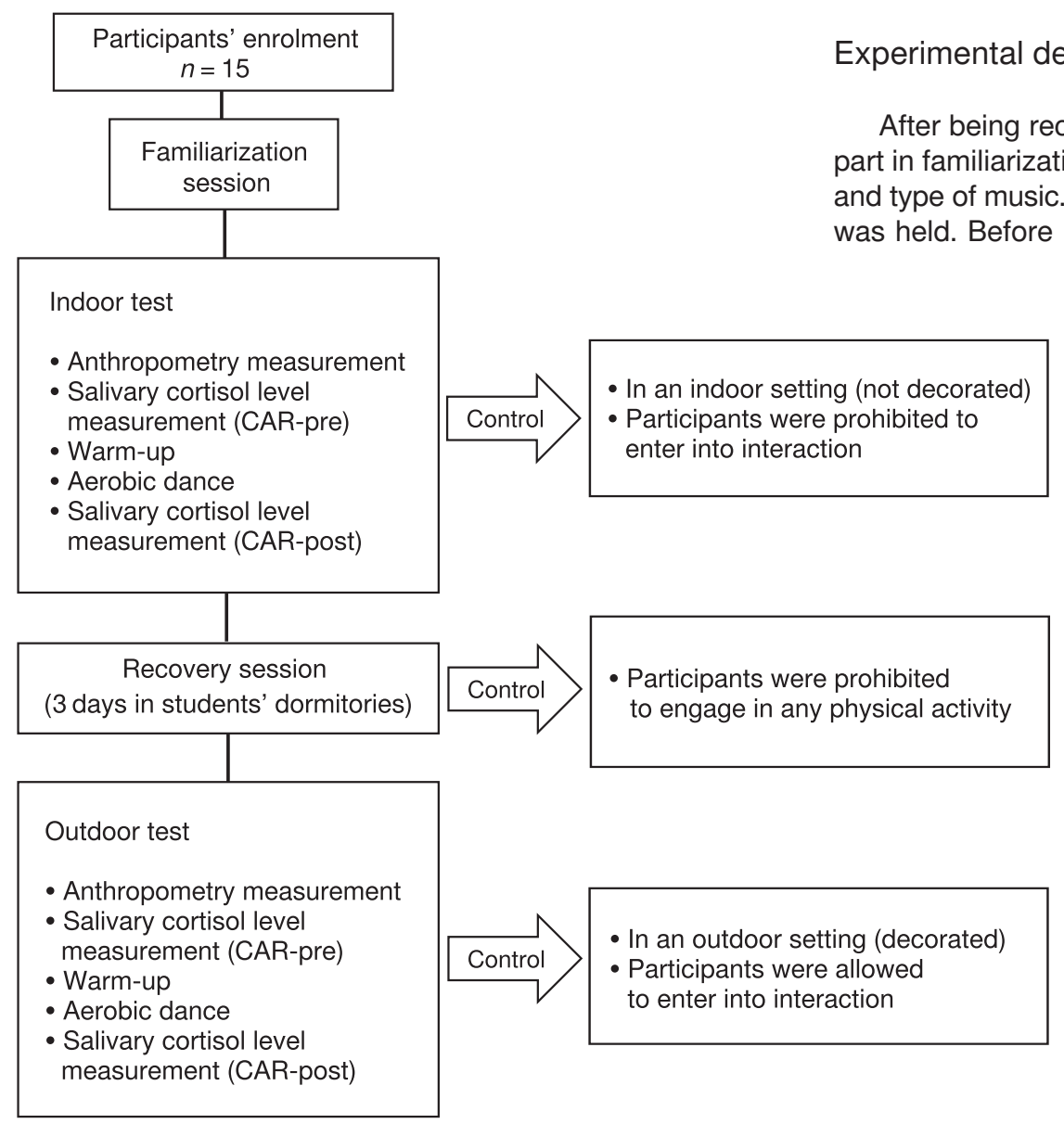

nut 4 software package; SCDA Nutrisoft, Cerelles, France) and the food composition tables published by the Tunisian National Institute of Statistics. The anthropometric characteristics of the participants are shown in Table 1.

Table 1. Anthropometric characteristics of the participants

\begin{tabular}{|l|c|c|}
\hline Variables & $\begin{array}{c}\text { Males } \\
\bar{x} \pm S D\end{array}$ & $\begin{array}{c}\text { Females } \\
\bar{x} \pm S D\end{array}$ \\
\hline Age (years) & $19.3 \pm 1.19$ & $19.6 \pm 0.92$ \\
\hline Weight $(\mathrm{kg})$ & $70.44 \pm 8.40$ & $59.65 \pm 2.88$ \\
\hline Height $(\mathrm{cm})$ & $178.3 \pm 4.47$ & $158.2 \pm 7.52$ \\
\hline BMI $\left(\mathrm{kg} / \mathrm{m}^{2}\right)$ & $22.14 \pm 2.50$ & $23.94 \pm 2.33$ \\
\hline
\end{tabular}

\section{Experimental overview}

The study used a parallel-purposive sampling in a pretestposttest design. Seven days before the indoor-test, all subjects received an introduction to the movements and types of music that would be used. After becoming familiar with the movements and music, they participated in the indoor test by doing aerobic dance in an undecorated room, with a length of $5 \mathrm{~m}$ and a width of $6 \mathrm{~m}$, being prohibited to enter into any type of interaction. The outdoor test was conducted 3 days after the last day of the indoor test. In the outdoor-test phase, all students took part in outdoor aerobic dance activities in an environment which had been decorated by the decoration team, thus giving the impression of an attractive natural setting for each participant. In this outdoor test, the subjects were allowed to interact. Salivary cortisol measurements were performed before and after each aerobic dance during the indoor- and outdoor-test phases. The research design is illustrated in Figure 1.

\section{Experimental design} and type of music. Seven days later, the indoor-test session was held. Before undergoing the indoor test, the students
CAR-pre - cortisol awakening response (salivary cortisol) before aerobic dance, CAR-post - cortisol awakening response (salivary cortisol) after aerobic dance Figure 1. Research design 

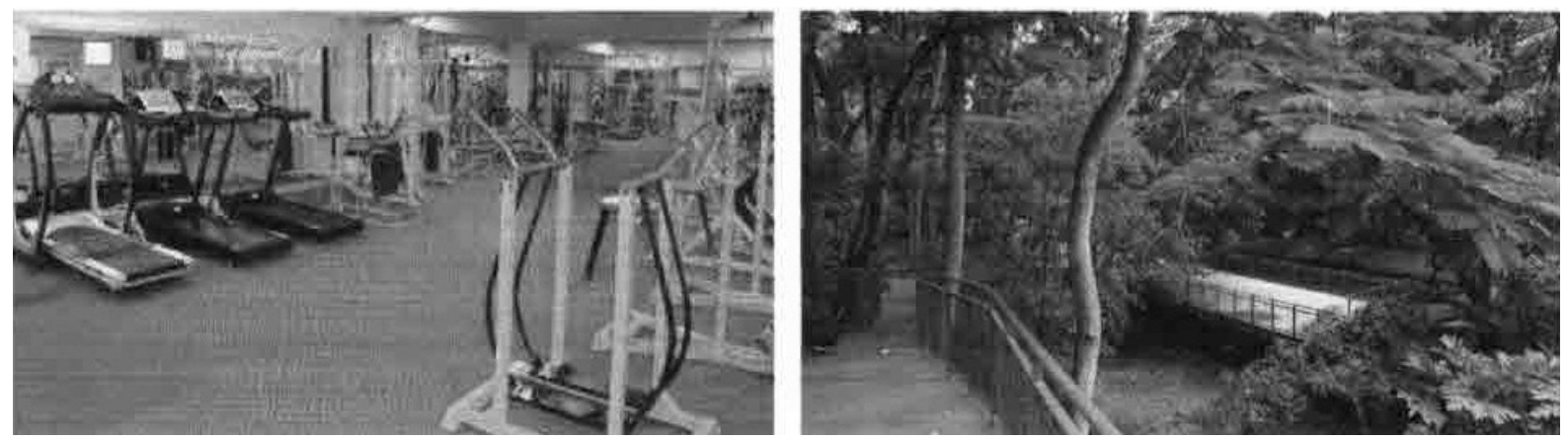

Figure 2. The undecorated room setting and the outdoors in a park close to the university

were asked to take a light dinner (before 09:00 p.m.) on the day before and not to eat food or drink caffeine beverages on the test day. The following morning at 06:00 a.m. (within the first 30 minutes after awakening), a saliva sample was collected from each participant to measure cortisol level. After the saliva sample collection, anthropometric measurements were taken. Body weight and body fat percentage were measured by Omron HBF-375 Karada Scan Body Composition Scale, with the subjects wearing minimal clothes and being barefoot. Body height was assessed with a stadiometer with $0.1 \mathrm{~cm}$ readability (Seca 214 portable stadiometer, Cardinal Health, Dublin, Ohio, USA) in accordance with the described standardized procedures. Body mass index was calculated as the ratio of body mass $(\mathrm{kg})$ and body height squared $\left(\mathrm{m}^{2}\right)$.

Then, prior to indoor testing, all participants performed a 15-minute standardized warm-up. The indoor test began at 8:30 a.m. and each subject was only required to follow the aerobic dance movements presented by the instructor, without engaging in social interactions such as communicating with one another or making sounds to the music rhythm, e.g. screaming or singing along. Furthermore, in this indoortest session, the room used to do the aerobic dance was not decorated, so it did not make an interesting impression on the participants. After the end of the last task section, the students were allowed to drink water ad libitum and encouraged to maintain hydration. Thirty minutes after the aerobic dance was finished, salivary cortisol level measurements were conducted again. Additionally, heart rate was monitored during the aerobic dance with a Polar RS400 device (Polar, Kempele, Finland).

After salivary cortisol level measurements, all students lived for 3 days in their dormitories and followed the same nutrition guidelines as those provided by the nutrition team during the study period. They were prohibited from carrying out physical activities during these 3 days with the aim of maximizing the recovery process. After 3 days of recovery, the outdoor test was carried out, which followed the baseline rules of the indoor test. However, in this outdoor-test session, all participants remained in an environment that was in direct contact with nature. The decoration team made suitable modifications so that all subjects could enjoy doing the aerobic dance. Furthermore, the students were allowed to interact with one another and make sounds to the rhythm of the music, but they were required to remain focused on the movements presented by the aerobic dance instructor. The indoor and outdoor settings are displayed in Figure 2.

\section{Rating of perceived exertion}

The aerobic dance physical effort intensity was assessed with session rating of perceived exertion (RPE) by using the applied to indicate exercise intensity to monitor training and competition load. The data were collected immediately after finishing the aerobic dance. The participants answered a simple question: How hard was your aerobic dance workout? A chart showed the outline of the full session RPE (CR-10 scale) with the appropriate explanations.

\section{Salivary cortisol measurements}

Whole collected saliva samples were analysed. For each assessment, the participants were asked to accumulate saliva in their mouth for 2 minutes and refrain from swallowing while doing so. The accumulated saliva was then transferred into a pre-labelled vial via a straw. Cortisol levels $(\mu \mathrm{g} / \mathrm{dl})$ were evaluated by using the instrument of Bio-Rad Model 680 microplate reader (Bio-Rad Laboratories, Inc., Hercules, CA, USA) and the software of Microplate Manager ver. 5.2.1 (BioRad Laboratories, Inc., Hercules, CA, USA); the High Sensitivity Salivary Cortisol Enzyme Immunoassay ${ }^{\circledR}$ Reagent Kit was applied at the Prodia Laboratory.

\section{Statistical analysis}

The values are presented as means $\pm S D$. The repeated measurement, ANOVA, and independent $t$-test were used to evaluate salivary cortisol before and after the aerobic dance, heart rate, and RPE in each indoor and outdoor test. The 95\% confidence intervals and change percentages were calculated. Statistical significance was accepted at the $p<0.05$ level as indicated by the SPSS software, V.21.0.

\section{Ethical approval}

The research related to human use has complied with all the relevant national regulations and institutional policies, has followed the tenets of the Declaration of Helsinki, and has been approved by the ethics committee of the Poltekkes Bandung.

\section{Informed consent}

Informed consent has been obtained from all individuals included in this study.

\section{Results}

To reveal the differences in salivary cortisol before the aerobic dance, heart rate during the aerobic dance, salivary cortisol after the aerobic dance, and RPE after the aerobic dance in the indoor-test and outdoor-test conditions, the oneway ANOVA and independent $t$-test were used (Tables 2 and 3 , respectively). 
Table 2. The effect of social and environmental interactions on salivary cortisol, heart rate, and rating of perceived exertion

\begin{tabular}{|l|c|c|c|}
\hline \multirow{2}{*}{ Variables } & Indoor test & Outdoor test & \multirow{2}{*}{${\text { ANOVA } p \text { values }^{\mathrm{a}}}^{2}$} \\
\cline { 2 - 4 } & $\bar{x} \pm S D$ & $\bar{x} \pm S D$ & 0.563 \\
\hline CAR-pre $(\mu \mathrm{g} / \mathrm{dl})$ & $0.12 \pm 0.05$ & $0.11 \pm 0.03$ & 0.955 \\
\hline HR $(\mathrm{bpm})$ & $182.3 \pm 6.80$ & $182.12 \pm 5.64$ & 0.001 \\
\hline CAR-post $(\mu \mathrm{g} / \mathrm{dl})$ & $0.58 \pm 0.16^{*}$ & $0.32 \pm 0.09^{*}$ & 0.136 \\
\hline
\end{tabular}

Indoor test - aerobic dance in indoor conditions, outdoor test - aerobic dance in outdoor conditions, CAR-pre - cortisol awakening response (salivary cortisol) before aerobic dance, HR - average heart rate during aerobic dance, CAR-post - cortisol awakening response (salivary cortisol) after aerobic dance, RPE - rating of perceived exertion after aerobic dance. Values are presented as means $\pm S D$.

${ }^{a}$ Repeated measures ANOVA.

*Values significantly different between the indoor- and outdoor-test $(p<0.05)$.

Table 3. Specific changes in salivary cortisol, heart rate, and rating of perceived exertion in the indoor and outdoor conditions

\begin{tabular}{|c|c|c|c|c|c|c|c|c|c|c|}
\hline \multirow{2}{*}{ Variables } & \multirow{2}{*}{$\begin{array}{l}\text { Measurement } \\
\text { conditions }\end{array}$} & \multicolumn{2}{|c|}{$\begin{array}{l}\text { Levene's test for } \\
\text { equality of variances }\end{array}$} & \multirow{2}{*}{$t$} & \multirow{2}{*}{$d f$} & \multicolumn{3}{|c|}{$t$-test for equality of means } & \multicolumn{2}{|c|}{$\begin{array}{c}95 \% \mathrm{Cl} \\
\text { of difference }\end{array}$} \\
\hline & & $F$ & Sig. & & & $\begin{array}{c}\text { Sig. } \\
\text { (2-tailed) }\end{array}$ & $\begin{array}{c}\text { Mean } \\
\text { difference }\end{array}$ & $\begin{array}{c}S D \text { of } \\
\text { difference }\end{array}$ & Lower & Upper \\
\hline \multirow{2}{*}{ CAR-pre $(\mu \mathrm{g} / \mathrm{dl})$} & Indoor test & 1.028 & 0.319 & 0.585 & 30 & $0.563^{*}$ & 0.009 & 0.015 & -0.022 & 0.041 \\
\hline & Outdoor test & & & 0.585 & 25.884 & $0.563^{*}$ & 0.009 & 0.015 & -0.023 & 0.041 \\
\hline \multirow{2}{*}{ HR (bpm) } & Indoor test & 0.484 & 0.492 & 0.057 & 30 & $0.955^{*}$ & 0.125 & 2.208 & -4.385 & 4.635 \\
\hline & Outdoor test & & & 0.057 & 29.019 & $0.955^{\star}$ & 0.125 & 2.208 & -4.392 & 4.642 \\
\hline \multirow{2}{*}{ CAR-post $(\mu \mathrm{g} / \mathrm{dl})$} & Indoor test & 2.627 & 0.116 & 5.811 & 30 & $0.001^{*}$ & 0.264 & 0.045 & 0.171 & 0.356 \\
\hline & Outdoor test & & & 5.811 & 24.743 & $0.001^{*}$ & 0.264 & 0.045 & 0.170 & 0.357 \\
\hline \multirow{2}{*}{ RPE } & Indoor test & 8.324 & 0.007 & -1.534 & 30 & $0.136^{*}$ & -0.250 & 0.162 & -0.582 & 0.082 \\
\hline & Outdoor test & & & -1.534 & 28.426 & $0.136^{*}$ & -0.250 & 0.162 & -0.583 & 0.083 \\
\hline
\end{tabular}

Sig. - significance, CAR-pre - cortisol awakening response (salivary cortisol) before aerobic dance, HR - average heart rate during aerobic dance, CAR-post - cortisol awakening response (salivary cortisol) after aerobic dance, RPE - rating of perceived exertion after aerobic dance, indoor test - aerobic dance in indoor conditions, outdoor test - aerobic dance in outdoor conditions. Values are presented as means $\pm S D$. Statistical analysis with independent $t$-test.

* Values significantly different between the indoor- and outdoor-test $(p<0.05)$.

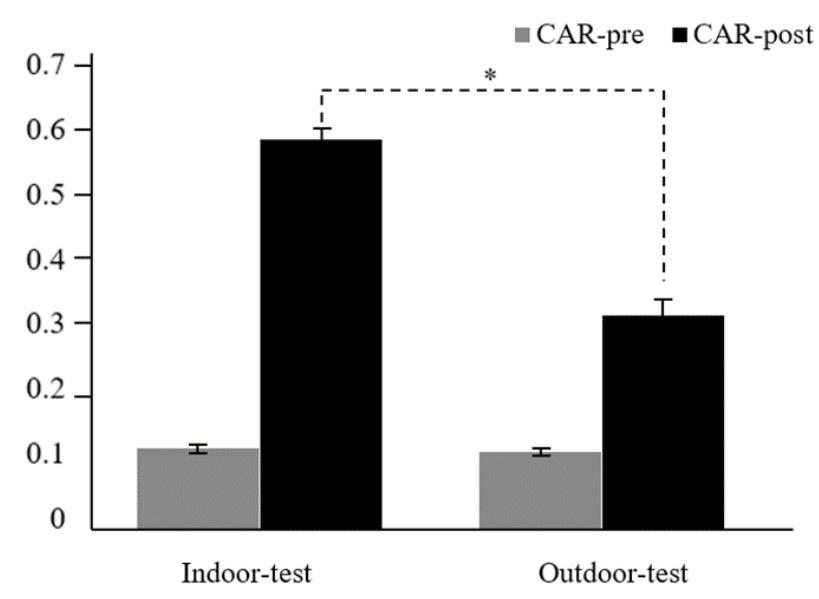

CAR-pre - cortisol awakening response (salivary cortisol) before aerobic dance, CAR-post - cortisol awakening response (salivary cortisol) after aerobic dance

* Significant difference between the indoor- and outdoor-test conditions $(p<0.05)$

Figure 3. Cortisol awakening response (mean $\pm S D)$ for all participants $(n=16)$ in the indoor test and outdoor test

\section{Salivary cortisol}

With regard to salivary cortisol values before the intervention, the one-way ANOVA statistical test results showed no significant difference between the indoor-test and outdoor-test conditions $(p=0.563)$. Likewise, the independent $t$-test revealed no significant difference between the two conditions ( $p=0.563)$. In turn, the one-way ANOVA statistical test presented a significant difference between the indoor-test and outdoor-test conditions in the salivary cortisol after the dance intervention $(p=0.001)$; the same result was obtained in the independent $t$-test $(p=0.001)$. Cortisol awakening response (CAR) values are shown in Figure 3.

\section{Average heart rate}

As for the average heart rate measurements during the indoor- and outdoor-test, the results of the one-way ANOVA statistical test and the independent $t$-test showed no significant difference between the two conditions ( $p$ value of 0.955 and 0.955 , respectively).

\section{Rating of perceived exertion}

With reference to RPE in all participants after the indoorand outdoor-test, the one-way ANOVA statistical analysis 
test and the independent $t$-test revealed no significant difference between the two conditions, with the significance level of $p=0.136$ for both tests.

\section{Discussion}

The purpose of the study was to measure the effect of social interaction and environment when doing aerobic dance. With respect to the prior hypothesis, it was stated that the more communicative social interactions and more conducive outdoor factors directly in contact with nature in while doing aerobic dance could have a significant impact on salivary cortisol reduction. To the best of the authors' knowledge, this was the first study to assess salivary cortisol with the concept of social interaction and environmental (natural) conditions as an independent variable in its testing.

Salivary cortisol was chosen as a parameter to determine stress levels because CAR is a reliable measure of the acute responsiveness of the hypothalamic-pituitary-adrenal (HPA) axis and can serve as a useful index of adrenocortical activity [21]. Furthermore, a literature review previously explained that the HPA axis is a highly stress-responsive system and shows a strong diurnal pattern with the glucocorticoid cortisol as an end product [22]. Several protocols had been obeyed in measuring CAR in salivary cortisol. The one applied in the study consisted in establishing CAR before the aerobic dance (CAR-pre), during the first 30 minutes after the participant woke up from sleep, and then conducting CAR measurements 30 minutes after the aerobic dance was completed (CAR-post). The approach was chosen because previous literature reviews showed that CAR could increase by $50-70 \%$ during the first 30 minutes after waking from sleep and after completing exercise [23].

An increase was observed between the average CARpre and CAR-post values. These results support some previously conducted literature reviews [24-26], which implied that CAR might represent a combination of previous exercise load and upcoming stress [27]. More specifically, Anderson and Wideman [28] explained that the HPA axis activity depended on the intensity of the intervention (e.g. low, moderate, and vigorous) and the intervention type (e.g. aerobic vs. yoga).

Another phenomenon observed in this study was the stable average of heart rate in the indoor-test and outdoortest, followed by the stable average of RPE generated from the load during the aerobic dance. The aerobic dance conducted in the study was categorized as high-intensity exercise, resulting in an average heart rate and RPE in the high category [29]. Another point that needs to be noticed is that the increase in CAR was correlated with an increase in heart rate and RPE. According to previous studies conducted by Caetano et al. [30], the high correlations of cortisol response, the session RPE measurements of physical stress in both investigated game conditions, and the fatigue test results showed that session RPE could be used to monitor training and competition to avoid excess 'stress'. Caetano et al. [30] did not provide heart rate data; the present study could be treated as a novel evidence that RPE and heart rate were correlated with increasing CAR, so it can be used as a monitoring parameter to avoid excessive stress.

Furthermore, there was a significant decrease in CARpost between the indoor-test and outdoor-test conditions for all participants. This might indicate an influence of more communicative social interactions and more conducive environmental factors, allowing direct contact with nature, in the outdoor-test conditions. Pointing at the effect of environmental factors on decreasing CAR, the research supports several previous studies [19, 31]. Specifically, Calogiuri et al. [31] compared two conditions for doing sports, namely indoor and outdoor (natural) settings, as a workplace intervention and found that outdoor exercise in natural conditions could be a profitable way to manage stress and induce restoration among employees. They explained that green exercise in outdoor conditions could evoke enthusiasm and motivation among participants and reduce stress by decreasing CAR.

Although there were some difficulties in finding supportive literature related to the effect of more communicative social interaction on CAR reduction, this study seems to be similar to the one conducted by lizuka et al. [32] on the impact of playing Go on the cognitive function of elderly people (65 years old). The participants were divided into 2 groups, each involving 30 individuals, who played Go once a week for 2 months. However, the difference appeared in the way of playing. One group played Go face-to-face and were allowed to interact and verbally ask questions to the instructor and game partners, while the other group played Go not face-to-face and were not allowed to interact during games. lizuka et al. [32] concluded that playing board games faceto-face with others is more effective for cognitive function than playing alone because social interactions require recognizing the opponents' facial expressions and surrounding circumstances while playing, and talking with the instructors or other participants during group lessons. Although the study was different with regard to the measurement of variables, sample characteristics, and treatment of experiments, it is speculated that social interactions could affect a person's stress level. This is evidenced by the findings of the present study showing that social interactions when doing aerobic dance could reduce the participants' CAR.

Because of the effect of social interaction and the environment when doing aerobic dance, all trainers and practitioners of aerobic dance are encouraged to choose the outdoor setting for the exercise. Additionally, the importance of social interactions during aerobic dance was revealed as a factor that made the participants feel more relaxed and happy. This was clearly expressed by the reduction in CAR when more communicative social interaction and more favourable environment factors were applied.

\section{Limitations}

The study limitations involved lack of consideration of several physiologic variables (blood lactate concentration, blood glucose, etc.) that would allow to better describe the physiological effort of each participant in the aerobic dance, as well as some anthropometric measurements (e.g. abdominal fat), which, in accordance with some literature reviews, could be used as indicators of a person's stress level [33]. Furthermore, psychological measurements should be introduced to reveal more about the effect of social interaction and environment on CAR. Thus, a further study is needed to address the issues that have not been clearly investigated in this study.

\section{Conclusions}

More communicative social interactions and conducive outdoor environment directly in contact with nature in doing aerobic dance could have a significant effect on reducing CAR as reflected in salivary cortisol measurements. Further research is needed to explore the mechanism behind the CAR decline and to rectify the discrepancies found in the results of some studies. 


\section{Acknowledgments}

The authors would like to thank the Bandung Institute of Technology for providing data for the study. No financial support was required or provided for this study.

\section{Disclosure statement}

No author has any financial interest or received any financial benefit from this research.

\section{Conflict of interest}

The authors state no conflict of interest.

\section{References}

1. Chandra S. Mortality from the influenza pandemic of 1918-19 in Indonesia. Popul Stud. 2013;67(2):185-193; doi: 10.1080/00324728.2012.754486.

2. Rachmi CN, Li M, Baur LA. Overweight and obesity in Indonesia: prevalence and risk factors - a literature review. Public Health. 2017;147:20-29; doi: 10.1016/j.puhe.2017. 02.002 .

3. Azhari, Ishak S, Wilujeng LK. Relationship between physical activity, fitness, and body image with obesity among senior high school students at Banda Aceh municipality [in Indonesian]. Bul Penelit Sist Kesehat. 2009;12(3): 319-329.

4. Kusmana $D$. The profile of physical activity and coronary risk factors in Monica Jakarta survey. Med $\mathrm{J}$ Indones. 2001;10(1):34-41; doi: 10.13181/mji.v10i1.7.

5. Ministry of Health of Indonesia. Information on the health profile of Indonesia 2018 [in Indonesian]. Jakarta: Kemenkes RI; 2019.

6. Schroeder K, Ratcliffe SJ, Perez A, Earley D, Bowman C, Lipman TH. Dance for health: an intergenerational program to increase access to physical activity. J Pediatr Nurs. 2017;37:29-34; doi:10.1016/j.pedn.2017.07.004.

7. Quin E, Frazer L, Redding E. The health benefits of creative dance: improving children's physical and psychological wellbeing. Educ Health. 2007;25(2):31-33.

8. Duberg A, Hagberg L, Sunvisson H, Möller M. Influencing self-rated health among adolescent girls with dance intervention: a randomized controlled trial. JAMA Pediatr. 2013;167(1):27-31; doi: 10.1001/jamapediatrics.2013.421.

9. Jeong Y-J, Hong S-C, Lee MS, Park M-C, Kim Y-K, Suh C-M. Dance movement therapy improves emotional responses and modulates neurohormones in adolescents with mild depression. Int J Neurosci. 2005;115(12): 1711-1720; doi: 10.1080/00207450590958574.

10. Koch SC, Morlinghaus K, Fuchs T. The joy dance: specific effects of a single dance intervention on psychiatric patients with depression. Arts Psychother. 2007;34(4): 340-349; doi: 10.1016/j.aip.2007.07.001.

11. Murrock CJ, Gary FA. A culturally-specific dance intervention to increase functional capacity in African American women. J Cult Divers. 2008;15(4):168-173.

12. Weuve J, Kang JH, Manson JE, Breteler MMB, Ware JH, Grodstein F. Physical activity, including walking, and cognitive function in older women. JAMA. 2004;292(12): 1454-1461; doi: 10.1001/jama.292.12.1454.

13. Aubert AE, Seps B, Beckers F. Heart rate variability in athletes. Sports Med. 2003;33(12):889-919; doi: 10.2165/ 00007256-200333120-00003

14. Wunsch K, Meier M, Ueberholz L, Strahler J, Kasten N. Acute psychosocial stress and working memory performance: the potential of physical activity to modulate cognitive functions in children. BMC Pediatr. 2019;19:271; doi: 10.1186/s12887-019-1637-x.
15. Woodward EN, Walsh JL, Senn TE, Carey MP. Positive social interaction offsets impact of low socioeconomic status on stress. J Natl Med Assoc. 2018;110(4):371377; doi: 10.1016/j.jnma.2017.07.006.

16. Rutkowska K, Bergier J, Witkowski Z. Styles of coping with stress and locus of control in sporting situations in a group of young female football players. Hum Mov. 2014;15(1):60-64; doi: 10.2478/humo-2014-0004.

17. Rapolienè L, Skarbalienè A, Gedrimè L, Mockevičienè D, Razbadauskas A. The influence of psychosocial factors on distress expression. Fam Med Prim Care Rev. 2019;21(1):41-46; doi: 10.5114/fmpcr.2019.82978.

18. Gajewski M, Różycka-Tran J, van Le H. Psycho-physiological mechanism of energy transfer in the human body: myth or reality? Health Psychol Rep. 2019;7(4): 267-275; doi: 10.5114/hpr.2019.88624.

19. Blase KL, van Waning A. Heart rate variability, cortisol and attention focus during Shamatha quiescence meditation. Appl Psychophysiol Biofeedback. 2019;44(4): 331-342; doi: 10.1007/s10484-019-09448-w.

20. Foster $\mathrm{C}$. Monitoring training in athletes with reference to overtraining syndrome. Med Sci Sports Exerc. 1998; 30(7):1164-1168; doi: 10.1097/00005768-19980700000023.

21. Cozma S, Dima-Cozma LC, Ghiciuc CM, Pasquali V, Saponaro A, Patacchioli FR. Salivary cortisol and $\alpha$-amylase: subclinical indicators of stress as cardiometabolic risk. Braz J Med Biol Res. 2017;50(2):e5577; doi: 10.1590/1414-431X20165577.

22. Wegner M, Koutsandréou F, Müller-Alcazar A, Lautenbach $\mathrm{F}$, Budde $\mathrm{H}$. Effects of different types of exercise training on the cortisol awakening response in children. Front Endocrinol. 2019;10:463; doi: 10.3389/fendo.2019. 00463.

23. Rosmalen JGM, Oldehinkel AJ, Ormel J, de Winter AF, Buitelaar JK, Verhulst FC. Determinants of salivary cortisol levels in 10-12 year old children: a population-based study of individual differences. Psychoneuroendocrinology. 2005;30(5):483-495; doi: 10.1016/j.psyneuen. 2004.12.007.

24. Minetto MA, Lanfranco F, Tibaudi A, Baldi M, Termine A, Ghigo E. Changes in awakening cortisol response and midnight salivary cortisol are sensitive markers of strenuous training-induced fatigue. J Endocrinol Invest. 2008; 31(1):16-24; doi: 10.1007/BF03345561.

25. Gouarné C, Groussard C, Gratas-Delamarche A, Delamarche P, Duclos M. Overnight urinary cortisol and cortisone add new insights into adaptation to training. Med Sci Sports Exerc. 2005;37(7):1157-1167; doi: 10.1249/ 01.mss.0000170099.10038.3b.

26. Park JY, Hwang TK, Park HK, Ahn RS. Differences in cardiovascular and hypothalamic-pituitary-adrenal axis functions between high-altitude visitors and natives during a trek on the Annapurna circuit. Neuroendocrinology. 2014;99(2):130-138; doi: 10.1159/000363367.

27. Duclos M, Corcuff JB, Rashedi M, Fougère V, Manier G. Trained versus untrained men: different immediate postexercise responses of pituitary adrenal axis. A preliminary study. Eur J Appl Physiol Occup Physiol. 1997;75(4): 343-350; doi: 10.1007/s004210050170.

28. Anderson T, Wideman L. Exercise and the cortisol awakening response: a systematic review. Sports Med Open. 2017;3(1):37; doi: 10.1186/s40798-017-0102-3.

29. Green JM, McLester JR, Crews TR, Wickwire PJ, Pritchett RC, Lomax RG. RPE association with lactate and heart rate during high-intensity interval cycling. Med Sci Sports 
Exerc. 2006;38(1):167-172; doi: 10.1249/01.mss.0000 180359.98241.a2.

30. Caetano Júnior PC, Castilho ML, Raniero L. Salivary cortisol responses and session ratings of perceived exertion to a rugby match and fatigue test. Percept Mot Skills. 2017;124(3):649-661;doi:10.1177/0031512517704340.

31. Calogiuri G, Evensen K, Weydahl A, Andersson K, Patil G, Ihlebæk $C$, et al. Green exercise as a workplace intervention to reduce job stress. Results from a pilot study. Work. 2015;53(1):99-111; doi: 10.3233/WOR-152219.

32. lizuka A, Suzuki H, Ogawa S, Kobayashi-Cuya KE, Kobayashi $\mathrm{M}$, Inagaki $\mathrm{H}$, et al. Does social interaction influence the effect of cognitive intervention program? A randomized controlled trial using Go game. Int J Geriatr Psychiatry. 2019;34(2):324-332; doi: 10.1002/gps.5024.

33. Donoho CJ, Weigensberg MJ, Emken BA, Hsu J-W, Spruijt-Metz D. Stress and abdominal fat: preliminary evidence of moderation by the cortisol awakening response in Hispanic peripubertal girls. Obesity. 2011; 19(5):946-952; doi: 10.1038/oby.2010.287. 